\title{
Who's the daddy? A behavioral and genetic study of multiple paternity in a polygamous marine invertebrate, Octopus oliveri
}

\author{
Heather Ylitalo ${ }^{1}$, Thomas A Oliver $^{2}$, Iria Fernandez-Silva ${ }^{1,3}$, James B Wood ${ }^{1}$, Robert J Toonen ${ }^{\text {Corresp. } 1}$ \\ ${ }^{1}$ Hawai'i Institute of Marine Biology, University of Hawai'i at Mānoa, Kāne'ohe, Hawaii, United States \\ 2 Department of Oceanography, University of Hawai'i at Mānoa, Honolulu, Hawaii, United States \\ 3 Department of Genetics, Biochemistry and Immunology, University of Vigo, Vigo, Spain \\ Corresponding Author: Robert J Toonen \\ Email address: toonen@hawaii.edu
}

Octopus oliveri is a widespread and common rocky intertidal cephalopod that mates readily in the laboratory, but for which mating behavior has not been reported previously. Four sets of behavioral experiments were recorded wherein three males, small, medium \& large in varying order, were introduced to each of six females, for a total of 24 individual females and 12 individual males utilized in the experiments. Video analysis shows that successful mating occurred in each of the mount, reach and beak-to-beak positions. Mating was observed for all males, regardless of size relative to the female, or order of introduction. Females showed preference for the first male to which they were introduced in experimental pairings rather than any specific male trait, and mating time increased significantly with increasing female size. Five novel microsatellite markers were developed and used to test paternity in the eleven broods resulting from these experimental pairings. We found skewed paternity in each brood, with early male precedence and male size being the best predictors of parentage. Multiple paternity was observed in every experimental cross but was estimated to be comparatively low in the field, suggesting that sperm limitation might be common in this species. We saw no evidence of direct sperm competition in Octopus oliveri, but larger males produced significantly more offspring. This study contributes to the growing research on cephalopod mating systems and indicates that octopus mating dynamics might be more variable and complex than thought previously. 
1 Who's the daddy? A behavioral and genetic study of multiple paternity in a polygamous marine invertebrate, Octopus oliveri.

Heather Ylitalo $^{1}$, Thomas A Oliver ${ }^{2}$, Iria Fernandez-Silva ${ }^{1,3}$, James B. Wood ${ }^{1}$, Robert J. Toonen ${ }^{1}$

${ }^{1}$ Hawai'i Institute of Marine Biology, University of Hawai'i at Mānoa, Kāne‘ohe, Hawai'i, USA. ${ }^{2}$ National Oceanic and Atmospheric Association, Honolulu, Hawai'i, USA

${ }^{3}$ Department of Genetics, Biochemistry and Immunology, University of Vigo, Spain

11 Corresponding authors: Heather Ylitalo or Rob Toonen

12 E-mail: hylitalo@gmail.com

13 or

14 toonen@hawaii.edu

15 Ph: (808) 236-7401 or fax: (808) 236-7443 


\section{Abstract}

17

18

19

20

21

22

Octopus oliveri is a widespread and common rocky intertidal cephalopod that mates readily in the laboratory, but for which mating behavior has not been reported previously. Four sets of behavioral experiments were recorded wherein three males, small, medium \& large in varying order, were introduced to each of six females, for a total of 24 individual females and 12 individual males utilized in the experiments. Video analysis shows that successful mating occurred in each of the mount, reach and beak-to-beak positions. Mating was observed for all males, regardless of size relative to the female, or order of introduction. Females showed preference for the first male to which they were introduced in experimental pairings rather than any specific male trait, and mating time increased significantly with increasing female size. Five novel microsatellite markers were developed and used to test paternity in the eleven broods resulting from these experimental pairings. We found skewed paternity in each brood, with early male precedence and male size being the best predictors of parentage. Multiple paternity was observed in every experimental cross but was estimated to be comparatively low in the field, suggesting that sperm limitation might be common in this species. We saw no evidence of direct sperm competition in Octopus oliveri, but larger males produced significantly more offspring. This study contributes to the growing research on cephalopod mating systems and indicates that octopus mating dynamics might be more variable and complex than thought previously. 
37

38

39

40

41

42

43

44

45

46

47

48

49

50

51

52

54

\section{INTRODUCTION}

Multiple paternity, or the presence of numerous males fertilizing offspring in one brood, is common across many taxa, in both vertebrates and invertebrates (Toonen 2004; Daly-Engel et al. 2006; Cutuli et al. 2013). In mating systems where multiple paternity occurs, it is often common to have high rates of sperm competition, which occurs when sperm from two or more males compete to fertilize the ova of a female (Birkhead and Møller 1998; Birkhead and Pizzari 2002).

Within the Cephalopoda, sperm competition has been observed in a variety of squid and cuttlefish species in the form of mate guarding, sneaker males, sperm flushing and increased sperm allocation (Wada et al. 2010; Squires et al. 2015; Naud et al. 2016). In octopuses, sperm competition is believed to occur due to the presence of multiple mating, two oviducts in which to store sperm, and long-term sperm storage capabilities (Birkhead and Møller 1998; Hanlon and Messenger 1998; Wigby and Chapman 2004; Morse et al. 2018). Yet, mate guarding and sneaker behavior has been described in few species (Cigliano 1995; Tsuchiya and Uzu 1997; Huffard et al. 2010).

Male sperm precedence is the nonrandom utilization of one male's sperm over another's (Birkhead and Møller 1998). This can occur through female cryptic choice within the oviduct of the female, overt female rejection of sperm packets, or through male displacement of previously placed sperm packets by rival males. In nature, some animals show first male sperm precedence (Tennessen and Zamudio 2003), where the first males to inseminate a female produce the most fertilized gametes, while others exhibit a "last in, first out" strategy (Birkhead and Møller 1998). Among octopus, evidence of sperm precedence has only been reported in the southern blueringed octopus, Hapalochlaena maculosa (Morse et al. 2015; Morse et al. 2018) and an unnamed 
61 species of pygmy octopus in which the mechanism of sperm competition remains unknown

62 (Cigliano 1995). In both studies, males spent more time mating with a female that had

63 previously mated. Cigliano (1995) concluded that this pattern suggested that the second male

64 was somehow removing or displacing sperm from a previous male. Based on these studies, there

65 might be a trend among octopuses of the last male siring more offspring than the first male to 66 mate with the female.

Three previous studies have been conducted using microsatellites to determine whether multiple paternity was present in octopus broods, one with Graneledone boreopacifica (Voight and Feldheim 2009), one with Octopus vulgaris (Quinteiro et al. 2011), and the last with Octopus minor (Bo et al. 2016). Each of these studies confirmed that multiple paternity was occurring in these species, however they did not observe mating prior to collecting the eggs, so it is unknown

72 if mating behavior affected fertilization success. We wanted to test whether successive males also showed any evidence of sperm competition with previous mates in O. oliveri. We also asked whether any conspicuous male trait, such as body size or aggression, predicted the observed mating success. For example, large body size can be a predictor in determining mating success not only in octopuses, but across many taxa (Andersson and Iwasa 1996; Birkhead and Møller 1998; Huffard et al. 2010). In addition, larger body size might be an indicator to females of genetic superiority in survivability and trigger female choice, so we also wanted to test whether size is a predictor of mating success.

The male octopus has a modified third right arm called the hectocotylus, which he uses to transfer sperm packets (spermatophores) to the female (Anderson et al. 2013). A sperm mass is encapsulated along with an ejaculatory organ in each spermatophore. The tip of the hectocotylus

83 is characterized by a ligula and calamus. The male passes a spermatophore down the groove of 
84 the hectocotylized arm to either of the two distal oviducts of the female. As the spermatophore is

85 passed down through the penis and into the groove of the hectocotylus, osmotic pressure begins

86 to force water through the outer tunic of the spermatophore. The male reaches into the mantle of

87 the female with his hectocotylus and transfers the spermatophore to the distal oviduct where the

88 ejaculatory process begins (Anderson et al. 2013). The sperm mass is released from the

89 spermatophore and it travels up the oviduct and is stored in the spermathecae in either of the two

90 oviducal glands, along with the sperm from previously mated males (Wells 1978; Mann 1984;

91 Hanlon and Messenger 1998; Wodinsky 2008). Females can mate with multiple males before

92 laying eggs and can store sperm for up to 10 months in some species (Mangold 1987). The eggs

93 become fertilized as they travel through the oviducal gland and down the oviduct (Forsythe and

94 Hanlon 1988). As with many other species, Octopus oliveri females lay several strands of eggs,

95 each with multiple eggs, which they protect for approximately one month before hatching

96 (Ylitalo et al., 2014).

97 This study describes the mating behavior of a minimally studied intertidal cephalopod,

98 Octopus oliveri, and tests the following questions: Are all mating attempts successful? If not, do

99 females differentially reject copulation attempts based on male size or mate order? Is multiple

100 paternity present in this species? If so, what are the ratios of paternity for each male, and can we

101 detect evidence of sperm precedence in this species or differential success of males among

102 fertilized egg strands?

103

104 MATERIALS AND METHODS

105 Animal collection and husbandry 
108 Honolulu, Hawai'i, USA in the fall of 2010 through the summer of 2013 (over 100 individuals

109 collected, 70 different trips into the field). These collections were permitted under Hawai'i State

110 Department of Land and Natural Resources, Division of Aquatic Resources Special Activities

111 Permits \#HIMB-SAP2010, HIMB-SAP2011, HIMB-SAP2012 \& HIMB-SAP2013. Two to three

112 people would walk along the rock wall during the evening hours for one to three hours (between

113 7pm-12am) with a flashlight. When an octopus was found, it was collected by hand and

114 transferred to a five-gallon bucket. The males and females were kept in separate buckets. Adult

115 octopuses were weighed on a platform scale (wet weight) and transferred to tanks on Coconut

116 Island, Kāne'ohe. Each octopus was housed in an individual tank (38cm x $21 \mathrm{~cm} \times 23.5 \mathrm{~cm})$ with

117 a piece of coral or PVC pipe for shelter and a plastic well-ventilated lid. These tanks were then

118 placed in a large outdoor tank at the Hawai'i Institute of Marine Biology (HIMB) with constant

119 saltwater flow (30 gallons per minute) and ambient ocean temperature (mean temperature $25.5^{\circ} \mathrm{C}$

$120 \pm 0.6$ ). The octopuses were fed frozen shrimp or live crabs daily until satiated and the tanks were

121 cleaned after each feeding. Water temperature records were obtained though NOAA Tides and

122 Currents databases from the station located closest to the collection sites in Honolulu (Station ID

123 1612340) and at Coconut Island (Station ID 1612481). Females collected that laid eggs before

124 experimental trials began were considered to be representative of natural populations and were

125 not used in mating experiments. They were allowed to brood their eggs until natural senescence

126 and their eggs were tested as non-experimental indicators of paternity in the wild. We do not

127 report an animal use permit because cephalopods are not regulated by IACUC at the University

128 of Hawai'i at the time of this study. 
129

130

131

132

134

135

136

137

138

139

140

141

142

143

144

145

146

148

149

150

\section{Mating experiments}

For each series of mating experiments (four in total) six females and three males were chosen randomly from the available pool of collected octopuses (raw data provided in Supplementary S1). Each female was paired with each of the three males (one male at a time) for a total of 18 individual mating trials per set of experiments. The males were chosen with maximum variation in size, one being the largest, one smallest, and one midsize. Each of the six females had a different order of mates (i.e., female 1 with male A, B, C, female 2 with male B, C, A etc.) allowing for every possible pairing combination (Fig. 1).

All mating trials occurred at night, as this species is nocturnal (Ylitalo et al. 2014). Three 15-gallon $(61 \mathrm{~cm}$ x $32 \mathrm{~cm}$ x $32 \mathrm{~cm})$ tanks were set up with constant seawater flow (2 gallons per minute) and separated by black plastic to ensure that adjacent pairs did not influence the other octopuses. Sessions were recorded using a 6 LED USB PC Web Camera with the infrared filter

removed. A camera was mounted 100 centimeters above each tank (measured from the floor of the tank). A 48-LED illuminator infrared light was placed in front of each tank to illuminate the video without disturbing the octopuses.

The female was always placed in the tank first and allowed to settle for approximately 10 minutes. Then, the male was introduced and the trial would begin. Three pairs were filmed simultaneously, each pair with its own camera, during each experimental night. Trials lasted at least two hours and would end when the mating pair separated. Also, if a female tried to escape from the tank three times, the trial was ended as it was predicted the female would have escaped the male in the field. In some cases, this would mean the trial would last less than two hours. Videos were analyzed after all trials were completed. 
Spermatogenesis after mating has been explored in several cephalopods, often with sperm

152 production occurring immediately following copulation (Van Heukelem 1976; Hanlon and

153 Ament 1999). However, the rates of sperm production vary across individuals. Given this

154 knowledge, the males were allowed to rest one day (a conservative estimate based on the

155 literature) between sessions to allow for sperm regeneration.

156 The trial history of each female was recorded to analyze whether mate order or mate size

157 influenced the observed mating success. Mating success was described as the amount of time a

158 male spent mating with a female and the number of times he was able to complete the arch and

159 pump movements.

160 If an animal died before a trial could be carried out, the pairing could not occur and was

161 therefore removed from the total number of possible recorded trials. Sixty-two trials were

162 completed and over 125 hours of video were analyzed twice by the same observer (H. Ylitalo)

163 and once by another observer (J. Yamada) to ensure continuity between evaluations of behavior.

164 Three central behaviors were recorded: mating, fighting (agonistic behavior) and resting. A trial

165 was considered successful when any or all of these behaviors between the two octopuses were

166 recorded. Within these general categories, more specific interactions were described as follows.

167 Mating was described as the period starting with the male approaching the female and

168 feeling around her mantle and arms, attempting to insert the hectocotylus. When the

169 hectocotylus was inserted, the male would begin arch and pump movements. During the "arch"

170 movement, the male lifted the groove on the hectocotylized arm to the mantle, lining it up with

171 the penis inside the mantle cavity, giving the male a hunched appearance. This was followed by

172 the "pump", when the male inflated the mantle in a deep respiratory movement and exhaled

173 explosively, sending the spermatophore down the ridge of the arm and into the oviducal gland of 
174 the female (Wells and Wells 1972; Wodinsky 2008). The number of times a male completed

175 each arch and pump movement was recorded as well as the time between first inserting the

176 hectocotylus to the first arch and pump.

177 Fighting (agonistic behavior) was described as the period when at least one octopus

178 appeared to be trying to escape the other. Writhing arms (grappling), suckers pulling on skin

179 (arm pulling), and biting were observed, however no inking was ever noted. During fighting, the

180 hectocotylus was clearly not inserted in the female, but physical contact was necessary for

181 fighting to be recorded. In some instances, fighting would result in mating (generally in the

182 mount position), while in others the octopuses would separate and try to escape or a resting

183 period would begin. Fighting was not always followed by mating, nor was mating followed by

184 fighting, indicating forced copulation was not occurring.

185 Resting behavior was described as the period of time when neither octopus was touching

186 the other, but could be moving around the tank, or lying still so long as they were not interacting.

187 Individuals had to be apart from each other and the male could not have any arm inside the

188 female for resting to be recorded.

189 In addition to these three main behaviors, any instances of female behavior that could be

190 perceived as female choice were recorded. For instance, if a female was seen to approach the

191 male to begin mating, if a female did not mate with one male but did mate with others, or if a

192 female was seen to overtly remove a sperm packet during any trial, the act was recorded.

193

194 Behavioral data analyses

195 Differences between the amount of time spent mating, fighting or resting between the

196 first, second or third male to mate with the female were tested using the non-parametric 
197 Friedman rank test $\left(\mathrm{FR}_{\mathrm{X}}\right)$. The Friedman rank test was used because it is based on rank and

198 median, rather than mean and variance, and is appropriate for repeated measures, so it is robust

199 to the non-independence of males among replicates. Only females that mated with each of the

200 three males in their set were included in this analysis $(n=15)$.

201 To analyze the effect of mate size on mating, fighting, and resting duration, the non-

202 parametric Kruskal-Wallis $[\mathrm{KW}(\mathrm{x})]$ test was used ( $\mathrm{R}$ code for all analyses provided in

203 Supplementary S2). For this analysis, all trials $(n=46)$ were included except those of the females

204 that did not mate in any of their three trials $(n=16)$. Male size relative to female was calculated

205 by dividing female weight by male weight (grams) (see Supplementary Material). Males that

206 were within $15 \%$ of female weight were considered equal in size, those more than $15 \%$ below

207 female weight were classified as small, and those at least $15 \%$ above were classified as large

208 males. Similarly, male size relative to average male size $(n=12$ males $)$ in the sampled

209 population and female size relative to average female size $(n=24$ females $)$ in the sampled

210 population were calculated.

211 Finally, female mating choice among males was tested using the Chi-square test $\left(\chi^{2}\right)$ on

212 the subsample of trials $(n=27)$ in which females successfully mated with all three paired males

213 and were observed exhibiting behavior resembling female choice. All statistical tests were run in

214 R (Version 0.99.902 R Studio, Inc.).

215

216 Genetic analyses of paternity

217 Arm tip muscle tissue was collected from 11 adult females (those that laid eggs; 8

218 experimental and 3 wild caught) and 9 adult males (the males that were mated with the brooding

219 females). Egg strings from each clutch were collected one or two days before hatching and fixed 
220 in separate vials of $90 \%$ ethanol. Thirty-four individual eggs were sampled from 9-12 randomly

221 selected strands from each of the 11 broods of females. The number of eggs sampled was

222 determined using power analysis (see Supplement). Eggs were randomly sampled from the top,

223 middle, and bottom section of the egg strand and their locations were recorded. The paralarvae

224 were almost fully developed at this time to provide the most DNA possible. DNA extractions

225 were performed using the HotSHOT protocol on each embryo and adult muscular tissue sample

226 (Truett et al. 2000).

227

Microsatellite loci developed for Octopus vulgaris and Graneledone boreopacifica

228 (Greatorex et al. 2000; Voight and Feldheim 2009; Quinteiro et al. 2011) were tested for use in

229 Octopus oliveri, however they all failed to amplify a product. Therefore, species-specific

230 microsatellite primers were designed for Octopus oliveri (Fernandez-Silva et al. 2013). Initially,

23148 putative loci (raw sequences provided in Supplementary S3) were tested, but after screening,

232 only the 5 best sets of primers (Table 1) were optimized (Selkoe and Toonen 2006). The three-

233 tailed primer method described by Gaither et al. (2009) was then used in PCR amplification.

234 Two primer mixes were prepared for each individual to be genotyped. Primer mix A

235 consisted of $10 \mu \mathrm{l}$ each of 100mM primer Octoli_3R, Octoli_7R, Octoli_10R, Octoli_11R,

236 fluorescent yellow (NED), red (PET), green (VIC), and blue (6-fam) dye. In addition, there were

$2372.5 \mu 1$ of 100mM primer Octoli_3F-T1, Octoli_7F-T2, Octoli_10F-T4, and Octoli_11F-T3

238 (Table 1). The rest of the mixture comprised of $410 \mu \mathrm{l}$ of RNAse-free water $\left(\mathrm{H}_{2} \mathrm{O}\right)$. Primer mix

239 B used the same ratio of solutions as listed above for Primer mix A, however primers Octoli_17,

240 Octoli_18, Octoli_22, and Octoli_23 were used. Octoli_10, Octoli_11, and Octoli_18 were not

241 used in the final analysis due to multiple non-Mendelian peaks in amplification, but were kept in

242 the primer mixes to ensure no differences in amplification among samples would occur. Each 
243 individual PCR reaction mix contained $3 \mu \mathrm{l} 2 \mathrm{X}$ Multiplex MasterMix (from a QIAGEN

244 Multiplex PCR kit), $0.6 \mu 1$ 10X Primer mix as outlined above, $1.4 \mu \mathrm{l}$ RNAse free water, and $1 \mu \mathrm{l}$

245 template DNA (1:10 dilution of extraction) for a final reaction volume of $6 \mu 1$.

246 PCR amplification was completed on a Bio-Rad iCyler as follows: $95^{\circ} \mathrm{C}$ for 15 minutes

247 ( 1 cycle), followed by 35 cycles of $95^{\circ} \mathrm{C}$ for 30 seconds, $60^{\circ} \mathrm{C}$ or $62^{\circ} \mathrm{C}$ (see Table 1) for 90

248 seconds, $72^{\circ} \mathrm{C}$ for 60 seconds, followed by a final extension of $72^{\circ} \mathrm{C}$ for 30 minutes. Amplified

249 PCR products were visualized on an Applied Biosystems 3730X Genetic Analyzer at the

250 University of Hawai' $i$ at Manoa, and genotyped using Geneious version 6.7.1 (Biomatters,

251 (Kearse et al. 2012) following guidelines from Selkoe and Toonen (2006).

252

253 Parentage and multiple paternity analyses using genetic data

254 The maternal genotypes from each of the 11 broods were compared with the embryo

255 genotypes manually to ensure that at least one maternal allele was found for each embryo at each

256 locus, confirming Mendelian inheritance (after Selkoe and Toonen 2006). Then, after excluding

257 the maternal alleles one can make a conservative estimate of the number of sires contributing to a

258 brood by using the single-locus minimum (SLM) method of counting the number of non-

259 maternal alleles at each locus in the progeny, dividing the largest number by two (assuming all

260 males are heterozygotes), and rounding up (Toonen 2004; Jones 2005).

261 The program GERUD v. 2.0 was then used to evaluate the frequency of multiple

262 paternity within broods based on population allele frequencies to find the most likely umber of

263 paternal genotypes (Jones 2005; Croshaw et al. 2009). GERUD was also used to calculate the

264 expected exclusion probability for each locus and for the combined loci (see Supplementary S4).

265 Two of the experimental broods required the locus Octoli_17 to be excluded from the analyses, 
266 because inclusion consistently caused the GERUD software to crash.

267 Parentage was assessed using the maximum likelihood ratio program in CERVUS v. 3.0

268 (Marshall et al. 1998; Slate et al. 2000; Jones et al. 2010). The likelihood ratio is the probability

269 that the candidate parent is the true parent compared with the probability of an alternate

270 unrelated candidate parent. The program uses this ratio to determine the most likely father given

271 a known maternal genotype, a set of candidate paternal genotypes, and the brood genotypes.

272 CERVUS incorporates genotyping error, unsampled candidate parents, and missing genotypes

273 into the program analysis. Both strict (95\%) and relaxed (80\%) confidence in paternal

274 assignment was used, but did not alter the interpretation of the data, so only the $95 \%$ assignment

275 was used here (as recommended by Marshall et al. 1998).

276 Any offspring not assigned paternity at $95 \%$ confidence were then rerun through GERUD

277 to find potential paternal genotypes from the wild, under the assumption that wild males who

278 mated with females before collection sired the unassigned offspring. GERUD also calculates

279 how many offspring are assigned to each wild type male. To corroborate the number of eggs

280 assigned to paternal genotypes generated by GERUD, CERVUS was run again using only

281 unassigned eggs (at a 95\% confidence level). Finally, the program $f_{m m}$ was used to assess the

282 frequency of multiple mating in the natural population of Octopus oliveri using the genotypes of

283 broods of non-experimental females (Neff 2002). This program considers the number of loci, the

284 number of alleles and their frequencies, and reproductive skew. These results were used to

285 corroborate multiple paternity through the SLM and GERUD methods and to extrapolate rates of

286 multiple paternity in wild populations.

287 Differences in the ratio of offspring sired by experimental males were tested using chi-

288 squared test $\left(\chi^{2}\right)$, whereas ANOVA and Pearson's product-moment correlations were used to test 
289 for differences in: mating time, male order, male size, number of arch and pumps, and frequency

290 of removed sperm packets, on the number of eggs sired by each experimental male. The best

291 model of predictors was calculated using marginal likelihood ratio tests and AIC (Akaike

292 Information Criterion) model selection tables (see Supplementary S4).

293

294 RESULTS

295 Mating behavior in Octopus oliveri

296 Of 62 behavioral observations during attempted crosses between 36 individuals (24

297 females and 12 males), 46 trials included mating. This number was reduced from the expected

298 total ( 24 experimental females introduced to each of 3 males $=72$ attempted crosses) because a

299 few females died, escaped, or laid eggs before completing all three experimental mating trials.

300 As with most octopuses, the mating behavior observed both between individuals and

301 among multiple mating bouts within individuals was varied (Wells and Wells 1972; Huffard et

302 al. 2008). However, some general patterns emerge. The average time it took for the male to

303 approach the female and begin mating was 18 minutes (standard error $[\sigma]=17$ minutes), with the

304 shortest amount of time being 8 seconds and the longest 1 hour and 7 minutes. No obvious

305 courtship was seen in either behavior or body patterns for either male or female octopuses in

306 these trials. The male would touch the female all over her mantle and arms while searching for

307 the oviduct with his hectocotylus for approximately 30 seconds to one minute. Most mating

308 occurred in either the arm reach or mount position (sensu Wells 1978), however in 12 trials,

309 beak-to-beak mating (Rodaniche 1984) was observed (Fig. 2). The most a male was able to arch

310 and pump in one mating trial was 74 times, the least was 5 times, with an average of 25 times

311 during a single mating session ( $\sigma=18$ arch and pumps). The average time between each arch 
312 and pump was 2 minutes and 12 seconds ( $\sigma=1$ minute 26 seconds). Despite the lack of obvious

313 courtship leading up to copulation, during mating itself, the male was generally a dark brown-red

314 color and the female was a pale white, although this was not always seen.

315 Mating would end when either partner would detach from the other (generally the

316 female), either to begin fighting or resting. The longest uninterrupted mating duration was 1

317 hour and 33 minutes, but in general, each trial was characterized by many short bouts of repeated 318 mating, the shortest being approximately 1 minute in duration. The average time spent mating 319 (all short bouts added together) per trial was 1 hour $(\sigma=45$ minutes). In the 16 trials where no 320 mating occurred, variable times and combinations of both fighting and resting were observed.

321 The data from these final 16 trials were used in the size analysis but not in mating precedence 322 analyses, where only females who mated in all three trials were used.

324 Male precedence effect

We saw no evidence of a male precedence effect in our behavioral observations of mating. Fifteen of the 24 experimental females successfully mated with all three experimental males in these trials. From the perspective of the female (see Supplementary S4), there were no significant differences in the rate or duration of mating, fighting, or resting as successive males were presented (mating $\mathrm{FR}_{\mathrm{X}}=0.43, p=0.82$, fighting $\mathrm{FR}_{\mathrm{X}}=1, p=0.61$, resting $\mathrm{FR}_{\mathrm{X}}=1, p=$

$3300.81, n=15)$. Nor was there a difference in the number of arch and pumps seen during 331 successive mating trials $\left(\mathrm{FR}_{\mathrm{X}}=0.32, p=0.81, n=15\right)$. Likewise, there was no significant 332 difference in the time it took for males to begin the first arch and pump between successive 333 mating trials $\left(\mathrm{FR}_{\mathrm{X}}=1.56, p=0.46, n=9\right)$. The same is true of the individual behavioral patterns 334 of the males (see Supplementary S4), in which no significant difference was found in response to 
335 successive females to which each was introduced (mating: $\mathrm{FR}_{\mathrm{X}}=0.4, p=0.81$, fighting: $\mathrm{FR}_{\mathrm{X}}=$

$3360.93, p=0.61$, resting: $\mathrm{FR}_{\mathrm{X}}=0.4, p=0.61$, number of arch and pumps: $\mathrm{FR}_{\mathrm{X}}=0.43, p=0.85$,

337 time from start of mating to first arch and pump: $\mathrm{FR}_{\mathrm{X}}=2, p=0.37, n=9$ ).

338

339

Effect of size on mating behavior

340 There was no significant trend (see Supplementary S4) between relative male size and the

341 likelihood of mating $(\mathrm{KW}(\mathrm{x})=0.31, p=0.85, n=52)$, resting $(\mathrm{KW}(\mathrm{x})=1.22, p=0.54, \mathrm{n}=52)$

342 or fighting $(\mathrm{KW}(\mathrm{x})=0.06, p=0.97, n=52)$ with a given female. Likewise, male size (either

343 absolute or relative to the female) did not appear to affect the number of times a male would arch

344 and pump $(\mathrm{KW}(\mathrm{x})=3.21, p=0.2, \mathrm{n}=52)$. Male size relative to other males (see Supplementary

$345 \mathrm{~S} 4)$, also had no significant effect on mating $(\mathrm{KW}(\mathrm{x})=1.92, p=0.38)$, fighting $(\mathrm{KW}(\mathrm{x})=2.32, p$

$346=0.31)$, resting $(\mathrm{KW}(\mathrm{x})=0.44, p=0.8)$, number of $\operatorname{arch}$ and pumps $(\mathrm{KW}(\mathrm{x})=0.37, p=0.83, n$

$347=52$ ). While male size did not appear to affect the course of mating trials, mating time and

348 the number of arch and pumps significantly increased with female size relative to other

349 females in the experiment. On average, larger females (see Supplementary S4) spent

350 significantly more time mating $(\mathrm{KW}(\mathrm{x})=6.7, p=0.03, n=52)$ and had significantly more arch

351 and pumps $(\mathrm{KW}(\mathrm{x})=8.38, p=0.01, n=52)$, whereas resting $(\mathrm{KW}(\mathrm{x})=3.36, p=0.18, n=52)$

352 and fighting $(\mathrm{KW}(\mathrm{x})=1.08, p=0.58, n=52)$ were not significantly impacted by female size.

353

354 Do females exhibit mate choice?

Females were significantly more likely to initiate mating with males introduced

356 earlier in the trials. There were 9 experimental females with at least one trial in which no

357 mating occurred. Neither male order $\left(\chi^{2}, p=0.79, n=18\right)$, male size relative to the female $\left(\chi^{2}, p\right.$ 
$358=0.53, n=23)$, male size relative to other males $\left(\chi^{2}, p=0.98, n=23\right)$, nor female size relative to 359 other females $\left(\chi^{2}, p=0.39, n=23\right)$ were significant in predicting a failure to mate. However, in

36013 of the 46 trials where mating behavior occurred, the female was the one to approach the male

361 to begin mating $\left(\chi^{2}, p=0.003, n=46\right)$, by either moving herself under the male or grabbing the

362 male to pull him on top of her. This behavior was exhibited by 9 of the 24 experimental females.

363 Significantly different from expectations, eight of these instances occurred with the first male

364 introduced to the female, 5 with the second male, and zero with the third $\left(\chi^{2}, p<0.01, n=27\right)$.

365 The size of the male relative to the female did not appear to be a factor in whether the female

366 would display this behavior; it occurred 6 times when the male was larger, 5 times when the

367 male was smaller and twice when the male was approximately equal in size to the female $\left(\chi^{2}, p=\right.$

$3680.34, n=27)$. Neither did the size of the female appear to be a factor in this behavior; 2 small, 3

369 medium, and 4 large females approached the male to initiate mating $\left(\chi^{2}, p=0.62, n=27\right)$. Six

370 of the nine females that exhibited this behavior laid eggs soon after the trials were concluded.

371 Thirteen of the 24 experimental females, in 19 different mating trials, were observed

372 removing an intact sperm packet. While we observed females removing sperm packets during

373 mating trials, none of the male traits we tested showed significant correlations to this behavior.

374 Removal happened either by the female exhaling forcefully and expelling the spermatophore (32

375 instances total), or the female moving her arms close to the mantle opening and "pulling" out the

376 sperm packet ( 2 observations). In each instance, the removal occurred while the male was in the

377 tank with the female. There did not appear to be any pattern among mate order or size to this

378 observed behavior. In 8 instances, females removed sperm packets from the first male, 7

379 instances from the second male and 4 from the third $\left(\chi^{2}, p=0.61, n=24\right)$, male regardless of

$380 \operatorname{size}\left(\chi^{2}, p=0.81, n=24\right)$. 
382

383

384

385

386

387

388

389

390

391

392

393

394

395

396

397

398

399

400

401

402 403 third experimental males (Fig. 4).

\section{Genetic analyses of paternity of broods}

Multiple paternity was confirmed in all experimental broods, and all but one of the nonexperimental broods when analyzed manually with the conservative single-locus minimum (SLM) method. Likewise, when analyzed with GERUD, at least 2 sires were determined for both experimental and non-experimental females, indicating multiple paternity in all broods tested (see Supplementary S4). Despite the universal finding of multiply mated females in this experiment, $f_{m m}$ calculated an expected frequency of multiple mating in the population at only $37 \%($ fmm unequal skew $=37 \%[2 \%-90 \%]$, fmm equal skew $=37 \%[1 \%-93 \%])$.

Analysis of the parentage of broods in CERVUS showed a trend of first mating precedence in experimental egg fertilizations (Fig. 3 and Supplementary S4); females used significantly more sperm from the first male to mate $\left(\chi^{2} 95 \% \mathrm{CI} ; p<0.01, n=8, \chi^{2} 80 \% \mathrm{CI} ; p=\right.$ $0.01, n=8)$. Likewise, the number of offspring sired by first males differed significantly $(p<$ 0.01) from the number sired by last males to mate (Fig. 3), but there was no pattern of male dominance within egg strands. Multiple males were found to have sired offspring within each strand tested, and distribution of paternity among strands appeared to be random.

When the eggs unassigned to a known male were rerun in GERUD and CERVUS, the category of "other" was split up into much smaller subsets (see Supplementary S4). The number of fathers that accounted for the unassigned eggs ranged from 2 to 6 , suggesting that these females had mated prior to being brought into the lab for experimental trials. Rerunning the parentage analysis with these males considered shows a significant difference $(p<0.01)$ in the proportion of eggs sired by the wild males and first experimental males versus the second and 
405 behavior and the proportion of eggs sired based on: male mating order, male body mass, number 406 of arch and pumps during each trial, time spent mating during a trial, the number of instances

407 where a female was seen removing a sperm packet in a trial, and the male size relative to the 408 female (smaller, equal, or larger). Running an ANOVA and plotting each of the variables alone 409 against the percentage of eggs sired showed a positive correlation in the size of the male in 410 grams $(p<0.001)$, the number of arch and pumps in a trial $(p<0.05)$, and the removal of sperm 411 packets during a trial $(p<0.05)$ with paternity. In contrast, mate order $(p<0.001)$ and mating 412 time $(p<0.01)$ show significant negative correlations with the percentage of eggs sired by that 413 male, whereas there was no relationship was detected in the relative size of males to females.

414 Thus, the largest females might be most attractive to males, but male size has no bearing on 415 whether mating would occur. Analyzing the data in this way might cause overfitting of the 416 model, especially given the small sample size and large number of parameters, so we also used 417 AIC to determine which variables were the most useful predictors. Using AIC, only the male 418 order and body mass were included as predictive variables in the best model (Table 2 and 419 Supplementary S4).

420

\section{DISCUSSION}

422 Mating behavior of Octopus oliveri

423

424

In general, the mating behavior of Octopus oliveri appears typical of other published 425 reports in the genus (Mangold 1987; Forsythe and Hanlon 1988). The only deviation of note is 426 the beak-to-beak mating, which although observed was still relatively uncommon ( $25 \%)$.

427 Rodaniche (1991) was the first to describe beak-to-beak mating in the larger Pacific striped 
428 octopus; in his observations, however, beak-to-beak was the only mating position exhibited by

429 that species. In Octopus oliveri, the mount, reach, and beak-to-beak mating positions were all

430 observed for the first time in a single species, and parentage confirms that all positions can result

431 in successful fertilization for this species.

432 Beak-to-beak mating is considered a dangerous position for the male, because sexual

433 cannibalism has been observed in a number of octopus species (Hanlon and Forsythe 2008).

434 Cannibalism did occur among non-experimental Octopus oliveri when housed in a large

435 communal tank but it was unclear if it was sexual cannibalism, competitive, or for other reasons.

436 No cannibalism was observed in any of the experimental mating trials but that does not rule out

437 the possibility that it might occur in the wild, and the fact that cannibalism occurs in communal

438 tanks suggests that males might be wary of mating in a position that would make them

439 vulnerable to consumption. This risk might account for the relative rarity of beak-to-beak

440 mating. Still, our results indicate such mating happens successfully, because of the nine females

441 who had trials where beak-to-beak mating occurred, five subsequently laid eggs. Chemical cues

442 have been found to be important in squid, octopus, and cuttlefish mating (Buresch et al. 2004;

443 Boal 2006; Cummins et al. 2011; Polese et al. 2015; Morse et al. 2016), so it is possible that the

444 males in these trials might have been responding to a chemical cue from the female inviting more 445 risky mating behavior.

446 Larger females tended to incite longer mating durations with higher numbers of arch and

447 pumps by males. Size in octopuses is generally dependent on environmental factors such as food 448 quality and temperature and it can therefore be difficult to determine what size determines sexual 449 maturity in a female (Semmens et al. 2004). However, in some octopuses size can be a predictor 450 of maturity and fecundity, which might indicate that males are more likely to invest time in 
451 mating with larger females (Huffard et al. 2008; Leporati et al. 2008; Mohanty et al. 2014). In

452 the case of Octopus oliveri, it also appears that larger females are more amenable to mating,

453 possibly because they are closer to spawning, or perhaps because they produce more eggs to

454 fertilize. While it is well known that female octopuses can mate and store sperm months before

455 laying eggs (Wells 1978; Anderson et al. 2013), it might be that the quality of the sperm is

456 reduced over time (Reinhardt 2007), making it likely that smaller females would be more likely

457 to delay mating until they are closer to spawning.

458

459 Female choice in mating

460 Initially, we interpreted the first approach by females and sperm removal as evidence of

461 female choice. However, both behaviors might be better explained by alternative hypotheses.

462 While it was a relatively rare occurrence for females to approach males for mating ( $28 \%)$, it is

463 significant that in more than $60 \%$ of these cases, it was the first male presented to the female,

464 regardless of size difference (Fig. 3). This preference might indicate that mature females isolated

465 from males would be more responsive to mating with the first male that is presented to them. If

466 so, that would suggest that male encounter rate in the wild is not so high as to avoid sperm

467 limitation, and that multiple mating might be a strategy to avoid reduced fertilization rate.

468 Therefore, the first approach by females might not be choice, but rather desperation due to sperm

469 limitation. Clearly studies in the field to observe this octopus mating would be beneficial, but

470 field observations of this species are rare and extremely difficult because they live exclusively in

471 high wave action areas with dangerous rocky terrain and are nocturnal.

472 A previous study of Octopus bimaculoides mating behavior found a similar pattern to that

473 in this study, with large females mating for longer periods with the first male to approach them 
474 (Mohanty et al. 2014). But, as with our results, it might be possible that as more mates are

475 presented to them, females might become more selective. Also, of the nine females who

476 exhibited primary approach behavior, six of them laid eggs at the end of the experiments. The

477 other three died, two during a water failure, and the last died unexpectedly, without laying eggs,

478 but it is notable that every individual that survived successfully laid eggs. As suggested by

479 Mohanty et al. (2014), if these females were nearing brooding, they might have been trying to

480 acquire as much sperm as possible.

481 Active sperm removal might be a function of female choice, particularly if it were also a

482 signal to the male that the female was not receptive to mating. However, it might also be simply

483 mechanistic, which is more likely the case in this study. Wodinsky (2008) reports on mating of

484 two Octopus species and noted that females were seen to expel spermatophores before the

485 spermatozoa within the spermatophore had ejaculated. He concluded it was a result of a

486 disconnection between the calamus (the tip of the hectocotylus) and the distal oviduct. If this

487 disconnection were the cause, the observed active removal of sperm packets would have nothing

488 to do with female choice. Given that there was no pattern among male size or precedence in

489 incidences where the females were observed to remove sperm packets, it would suggest that any

490 male could place the ligula incorrectly. In this case, if the sperm removal were mechanistic, it

491 would indicate that no female choice is occurring; rather it is a function of clearing the passage

492 to the oviduct to allow further spermatophores to be transferred. Given that we found a positive

493 correlation between the occurrence of sperm removal and paternity it suggests that this behavior

494 is indeed a result of misplaced spermatophores and not a function of choice, because a negative

495 correlation between sperm removal and paternity would be expected if this behavior were a

496 function of choice. 
498 Multiple paternity

499 Our data confirm multiple paternity in Octopus oliveri in every experimental mating that

500 we conducted, but $f_{m m}$ suggests that the rate is only moderate in the field $\left(f_{m m}\right.$ unequal skew $=$

$50137 \%[2 \%-90 \%], f_{m m}$ equal skew $\left.=37 \%[1 \%-93 \%]\right)$. Added to reports of multiple paternity in the

502 deep sea octopus Graneledone boreopacifica (Voight and Feldheim 2009), the shallow water

503 Octopus vulgaris (Quinteiro et al. 2011), and the long-armed octopus Octopus minor (Bo et al.

504 2016), it appears that this reproductive outcome is the norm among octopods. The fact that

505 females tend to initiate mating most often with the first male to which they are introduced, and

506 then become more choosy as more mates are provided suggests that sperm limitation might be a

507 reasonable explanation. Likewise, if larger females were more fecund, that would be consistent

508 with the tendency for larger females to encourage prolonged mating time and increased numbers

509 of arch and pumps (and therefore more spermatophores) during mating.

510

511 Sperm competition and mating precedence

512 It has been reported that the ligula on the tip of the hectocotylus may be used to remove

513 sperm deposited by previous males (Cigliano 1995; Quinteiro et al. 2011). Unlike Cigliano's

514 experiments in 1995, our experiments did not show any evidence of a sperm competition

515 mechanism between males. There was no significant change in the amount of time between

516 when the male would insert his hectocotylus and when he would begin the arch and pump

517 movements, regardless of the mate order, absolute or relative body size. In addition, and in

518 contrast to what was found in the squid Loligo vulgaris reynaudii (Shaw and Sauer 2004), there 
519 was no clear distribution of sires among the individual strings or among the whole brood in $O$.

520 oliveri.

521 Such differences might result from variation among species in the tissue of the ligula and

522 calamus of octopuses that could impact the ability to displace spermatozoa of previous males

523 (Voight 2002; Thompson and Voight 2003). For example, the ligula of $O$. oliveri is very short

524 and lacks flexibility (Garcia 2010), so perhaps this limits their ability to remove sperm deposited

525 by previous males. Alternatively, the time between mating sessions might have been sufficient

526 to allow spermatozoa to penetrate deep into the spermatheca (De Lisa et al. 2013), therefore

527 rendering sperm removal difficult or impossible. For example, spermatozoa have been found in

528 the oviducal gland of $O$. tetricus one day (24h) after mating, although whether it was the sperm

529 of the experimental male or a previous male from the field was unclear (Joll 1976).

530 Studies examining precedence in cephalopods have focused predominantly on loliginid

531 squids and cuttlefish (Buresch et al. 2009; Voight and Feldheim 2009; Quinteiro et al. 2011; Sato

532 et al. 2016). Last male precedence was found in two squid species: Loligo bleekeri and Loligo

533 vulgaris reynaudii (Shaw and Sauer 2004; Iwata and Munehara 2005), and one cuttlefish species:

534 Euprymna tasmanica (Squires et al. 2015). In contrast, no clear precedence was found in the

535 cuttlefish Sepia apama (Naud et al. 2004). In both squid and cuttlefish, males can deposit sperm

536 packets (spermatangia) either inside the mantle, or around the buccal mass surrounding the

537 mouth, which leads to both external and internal fertilization. Possibly because many (but not all)

538 species of squid and cuttlefish mate in large aggregations, the last male to encounter the female

539 can ensure paternity by guarding the female while eggs are laid. In contrast, octopuses have only

540 internal fertilization, and contrary to last male precedence commonly reported in squids and

541 cuttlefish, we found early male precedence among our experimental mating trials in Octopus 
542 oliveri. However, this is not first male precedence because none of the females collected were

543 likely to be virgins, and the relative contribution of matings prior to the start of the experiment

544 cannot be accurately determined. Nonetheless, there is skew among every brood tested,

545 indicating that some males are fertilizing more offspring than others, and among our

546 experimental mating trials, the last males clearly sired significantly fewer offspring than the first

547 males (Fig. 3). One possible explanation for why the first males in our experiments did so well

548 in terms of fertilization success is that females captured for this experiment might have been

549 storing sperm for long enough that it had decreased in quality. When presented with a new male

550 at the outset of the experimental matings, these males might have been able to displace or

551 overwhelm the low-quality sperm of previous males. If this were the case, it is also possible that

552 the first male could have overwhelmed the spermathecae, making sperm depositions by

553 subsequent males less successful.

554 In addition to mating order, size was the only other predictive variable for parentage in

555 this study. Although size did not influence the ability of a male to mate in the behavioral

556 experiments, the use of the microsatellite markers indicates larger males sire significantly more

557 offspring. This could be due to some factor such as an unknown mechanism of differential use

558 of deposited sperm by the female, but we suspect that large males have larger spermatophores

559 and are sperm loading, or overwhelming the spermathecae with their sperm (Simmons and

560 Fitzpatrick 2012). There was no significant correlation between the number of arch and pumps

561 and the number of offspring sired, but larger males might contribute larger spermatophores

562 containing higher numbers of individual spermatozoa, thereby increasing their chances of

563 fertilization over smaller males. Among octopodids studied to date, spermatophore size tends to

564 be highly correlated with mantle length (Mann 1984). Each spermatophore contains a sperm 
565 reservoir, which contains the individual spermatozoa. Voight (2001) found that sperm reservoir

566 length is very tightly correlated with spermatophore length, suggesting that males are incapable

567 of manipulating the size (and therefore the number of spermatozoa) of the spermatophore to

568 maximize the amount of sperm delivered to the female. Although spermatophore size was not

569 measured in this study, we see only a correlation between male body mass, not numbers of arch

570 and pumps, in successful paternity of broods, leading us to hypothesize that larger males might

571 transfer more spermatozoa than smaller males. Further research is needed to determine if sperm

572 loading might be a sperm competition strategy in octopods.

573

574 Conclusion

575 These experiments indicate that females of Octopus oliveri appear to mate

576 indiscriminately with males in any order and of any size, showing minimal behavioral evidence

577 for pre-copulatory sexual selection. Successful mating occurred in each of the mount, reach and 578 beak-to-beak positions, and larger females elicited greater mating effort from males in terms of

579 duration and arch and pump behaviors. Multiple paternity was observed in every experimental 580 cross when females were presented with 3 potential mates under laboratory conditions but was 581 estimated to be comparatively low in the field. This low population rate of multiple paternity 582 might indicate sperm limitation due to rare mate encounter in the field and could explain both 583 female responses to first males in our behavioral assays and early male advantage in parentage of 584 broods. We see no evidence of direct sperm competition in Octopus oliveri, but larger males 585 produce significantly more offspring, perhaps because they can include more spermatozoa in 586 spermatophores. This study contributes to the growing research on cephalopod mating systems 
587 and indicates that octopus mating dynamics might be more variable and complex than thought 588 previously.

589

590 ACKNOWLEDGEMENTS

591

592 We thank the ToBo lab, especially Zac Forsman and Ingrid Knapp, for their assistance and

593 advice with the genetics component of this research, and to Jeff Drazen, Les Watling \& Chuck

594 Birkeland for their support and feedback throughout this project. This is contribution \#XXXX

595 from the Hawai'i Institute of Marine Biology, and SOEST \#YYYY. 


\section{LITERATURE CITED}

597

598

599

600

601

602

603

604

605

606

607

608

609

610

611

612

613

614

615

616

617

618

619

620

621

622

623

624

625

626

627

628

629

630

631

632

633

634

635

636

637

638

639

640

Andersson M, Iwasa Y (1996) Sexual selection. Trends in Ecology \& Evolution 11:53-58. doi: 10.1016/0169-5347(96)81042-1

Anderson, RC, Mather JA, Wood JB (2013) Octopus: The Ocean's Intelligent Invertebrate. Timber Press, Portland

Birkhead TR, Møller AP (1998) Sperm Competition and Sexual Selection. Academic Press, London

Birkhead TR, Pizzari T (2002) Postcopulatory sexual selection. Nature Reviews Genetics 3:262273.

Bo Q-K, Zheng X-D, Gao X-L, Li Q (2016) Multiple paternity in the common long-armed octopus Octopus minor (Sasaki, 1920) (Cephalopoda: Octopoda) as revealed by microsatellite DNA analysis. Marine Ecology 37:1073-1078. doi: 10.1111/maec.12364

Boal JG (2006) Social recognition: a top down view of cephalopod behaviour. Vie et milieu 56:69-80.

Buresch KC, Boal JG, Nagle GT, Knowles J, Nobuhara R, Sweeney K, Hanlon RT (2004) Experimental evidence that ovary and oviducal gland extracts influence male agonistic behavior in squids. Biol Bull 206:1-3.

Buresch KC, Maxwell MR, Cox MR, Hanlon RT (2009) Temporal dynamics of mating and paternity in the squid Loligo pealeii. Mar Ecol Prog Ser 387:197-203.

Cigliano JA (1995) Assessment of the mating history of female pygmy octopuses and a possible sperm competition mechanism. Animal Behaviour 49:849-851.

Croshaw DA, Peters MB, Glenn TC (2009) Comparing the performance of analytical techniques for genetic PARENTAGE of half-sib progeny arrays. Genet Res (Camb) 91:313-325. doi: 10.1017/S0016672309990231

Cummins SF, Boal JG, Buresch KC, Kuanpradit C, Sobhon P, Holm JB, Degnan BM, Nagle GT, Hanlon RT(2011) Extreme aggression in male squid induced by $\beta$-MSP-like pheromone. Current Biol 21:322-327. doi: 10.1016/j.cub.2011.01.038

Cutuli G, Cannicci S, Vannini M, Fratini S (2013) Influence of mating order on courtship displays and stored sperm utilization in Hermann's tortoises (Testudo hermanni hermanni). Behav Ecol Sociobiol 67:273-281.

Daly-Engel TS, Grubbs RD, Holland KN (2006) Assessment of multiple paternity in single litters from three species of carcharhinid sharks in Hawai' i. Environ Biol Fish 76:419-424

De Lisa E, Salzano AM, Moccia F, Scaloni A, Di Cosmo A (2013) Sperm-attractant peptide influences the spermatozoa swimming behavior in internal fertilization in Octopus vulgaris. J Exp Biol 216:2229-2237. doi: 10.1242/jeb.081885

Fernandez-Silva I, Whitney J, Wainwright B, Andrews KR, Ylitalo-Ward H, Bowen BW, Toonen,RJ, Goetze,E, Karl SA (2013) Microsatellites for Next-Generation Ecologists: A Post-Sequencing Bioinformatics Pipeline. PLoS ONE 8:e55990. doi: 10.1371/journal.pone.0055990

Forsythe JW, Hanlon RT (1988) Behavior, body patterning and reproductive biology of Octopus bimaculoides from California. Malacologia 29(1):41-45.

Garcia A (2010) Comparative study of the morphology and anatomy of octopuses of the family Octopodidae.

Greatorex EC, Jones CS, Murphy J, Key LN, Emery AM, Boyle PR (2000) Microsatellite markers for investigating population structure in Octopus vulgaris (Mollusca: Cephalopoda). 
641

642

643

644

645

646

647

648

649

650

651

652

653

654

655

656

657

658

659

660

661

662

663

664

665

666

667

668

669

670

671

672

673

674

675

676

677

678

679

680

681

682

683

684

685

686

Mol Ecol 9:641-642. doi: 10.1046/j.1365-294x.2000.00882-7.x

Hanlon R, Ament S (1999) Behavioral aspects of sperm competition in cuttlefish, Sepia officinalis (Sepioidea: Cephalopoda).

Hanlon RT, Forsythe JW (2008) Sexual cannibalism by Octopus cyanea on a Pacific coral reef. Marine and Freshwater Behaviour and Physiology 41:19-28.

Hanlon RT, Messenger JB (1998) Cephalopod Behaviour. Cambridge University Press

Huffard CL, Caldwell RL, Beneka F (2008) Mating behavior of Abdopus aculeatus (d'Orbigny 1834) (Cephalopoda: Octopodidae) in the wild. Marine Biology, 154(2): 353-362.

Huffard CL, Caldwell RL, Boneka F (2010) Male-male and male-female aggression may influence mating associations in wild octopuses (Abdopus aculeatus). Journal of comparative psychology (Washington, DC: 1983) 124:38.

Iwata Y, Munehara H (2005) Dependance of paternity rates on alternative reproductive behaviors in the squid Loligo bleekeri. Mar Ecol Prog Ser 298:219-228.

Joll LM (1976) Mating, egg-laying and hatching of Octopus tetricus (Mollusca: Cephalopoda) in the laboratory. Mar Biol 36:327-333.

Jones A (2005) GERUD 2.0: a computer program for the reconstruction of parental genotypes from half-sib progeny arrays with known or unknown parents. Mol Ecol Res 5(3):708-711.

Jones A, Small CM, Paczolt KA, Ratterman NL (2010) A practical guide to methods of parentage analysis. Mol Ecol Res 10(1):6-30.

Kearse M, Moir R, Wilson A, Stones-Havas S, Cheung M, Sturrock S, Buxton S, Cooper A, Markowitz S, Duran C, Thierer T, Ashton B, Meintjes P, Drummond A. (2012) Geneious Basic: an integrated and extendable desktop software platform for the organization and analysis of sequence data. Bioinformatics 28:1647-1649. doi: 10.1093/bioinformatics/bts199

Leporati SC, Pecl GT, Semmens JM (2008) Reproductive status of Octopus pallidus, and its relationship to age and size. Mar Biol 155:375-385. doi: 10.1007/s00227-008-1033-9

Mangold K (1987) Reproduction. In: Boyle PR (ed) Cephalopod Life Cycles, Vol. II: Comparative Reviews. Academic Press, London, pp 157-200

Mann T (1984) Spermatophores: development, structure, biochemical attributes and role in the transfer of spermatozoa. Springer-Verlag Berlin, Germany

Marshall TC, Slate J, Kruuk LE, Pemberton JM (1998) Statistical confidence for likelihoodbased paternity inference in natural populations. Mol Ecol 7:639-655.

Mohanty S, Ojanguren AF, Fuiman LA (2014) Aggressive male mating behavior depends on female maturity in Octopus bimaculoides. Mar Biol 1-10.

Morse P, Zenger KR, McCormick MI, Meekan MG, Huffard CL (2015) Nocturnal mating behaviour and dynamic male investment of copulation time in the southern blue-ringed octopus, Hapalochlaena maculosa (Cephalopoda: Octopodidae). Behaviour 152:1883-1910. doi: 10.1163/1568539X-00003321

Morse P, Zenger KR, McCormick MI, Meekan MG, Huffard CL. (2016) Chemical cues correlate with agonistic behaviour and female mate choice in the southern blue-ringed octopus, Hapalochlaena maculosa (Hoyle, 1883) (Cephalopoda: Octopodidae). J Mollus Stud. doi: 10.1093/mollus/eyw045

Morse P, Huffard CL, Meekan MG, McCormick MI, Zenger KR (2018) Mating behaviour and postcopulatory fertilization patterns in the southern blue-ringed octopus, Hapalochlaena maculosa. Animal Behaviour 136 (2018): 41-51.

Naud M-J, Hanlon RT, Hall KC, Shaw P, Havenhand J. (2004) Behavioural and genetic assessment of reproductive success in a spawning aggregation of the Australian giant

Peer) reviewing PDF | (2018:10:32128:1:1:NEW 14 Mar 2019) 
687

688

689

690

691

692

693

694

695

696

697

698

699

700

701

702

703

704

705

706

707

708

709

710

711

712

713

714

715

716

717

718

719

720

721

722

723

724

725

726

727

728

729

730

731

732

cuttlefish, Sepia apama. Animal Behaviour 67:1043-1050.

Naud M-J, Sauer WHH, McKeown NJ, Shaw PW (2016) Multiple Mating, Paternity and Complex Fertilisation Patterns in the Chokka Squid Loligo reynaudii. PLoS ONE 11:e0146995. doi: 10.1371/journal.pone.0146995.t001

Neff BD (2002) A Bayesian Model for Assessing the Frequency of Multiple Mating in Nature. Journal of Heredity 93:406-414. doi: 10.1093/jhered/93.6.406

Polese G, Bertapelle C, Di Cosmo A (2015) Role of olfaction in Octopus vulgaris reproduction. General and Comparative Endocrinology 210: 55-62.

Quinteiro J, Baibai T, Oukhattar L, Soukri A, Seixas P, Rey-Mendez M (2011) Multiple paternity in the common octopus Octopus vulgaris (Cuvier, 1797), as revealed by microsatellite DNA analysis. Molluscan Research 31:15-20.

R Core Team (2013) R: A language and environment for statistical computing. R Foundation for Statistical Computing, Vienna, Austria. http://www.R-project.org/

Reinhardt K (2007) Evolutionary consequences of sperm cell aging. Q Rev Biol 82:375-393.

Rodaniche AF (1984) Iteroparity in the lesser Pacific striped octopus Octopus chierchiae (Jatta, 1889). Bulletin of marine science 35:99-104.

Sato N, Yoshida M-A, Kasugai T (2016) Impact of cryptic female choice on insemination success: Larger sized and longer copulating male squid ejaculate more, but females influence insemination success by removing spermatangia. Evolution. doi: 10.1111/evo.13108

Selkoe KA, Toonen RJ (2006) Microsatellites for ecologists: a practical guide to using and evaluating microsatellite markers. Ecol Lett 9:615-629. doi: 10.1111/j.14610248.2006.00889.x

Semmens JM, Pecl GT, Villanueva R, Jouffre D, Sobrino I, Wood JB, Rigby PR. (2004) Understanding octopus growth: patterns, variability and physiology. Marine and freshwater research 55:367-377.

Shaw PW, Sauer WH (2004) Multiple paternity and complex fertilisation dynamics in the squid Loligo vulgaris reynaudii. Mar Ecol Prog Ser 270:173-179.

Simmons LW, Fitzpatrick JL (2012) Sperm wars and the evolution of male fertility. Reproduction 144:519-534. doi: 10.1530/REP-12-0285

Slate J, Marshall T, Pemberton J (2000) A retrospective assessment of the accuracy of the paternity inference program CERVUS. Mol Ecol 9:801-808.

Squires ZE, Wong BBM, Norman MD, Stuart-Fox D (2015) Last male sperm precedence in a polygamous squid. Biological Journal of the Linnean Society 116:277-287. doi: $10.1111 /$ bij. 12590

Tennessen JA, Zamudio KR (2003) Early male reproductive advantage, multiple paternity and sperm storage in an amphibian aggregate breeder. Mol Ecol 12:1567-1576.

Thompson JT, Voight JR (2003) Erectile tissue in an invertebrate animal: the Octopus copulatory organ. Journal of Zoology 261:101-108.

Toonen RJ (2004) Genetic evidence of multiple paternity of broods in the intertidal crab Petrolisthes cinctipes. Mar Ecol Prog Ser 270:259-263.

Truett GE, Stones-Havas S, Cheung M, Sturrock S, Buxton S, Cooper A, Markowitz S, Duran C, Thierer T, Ashton B, Meintjes P, Drummond A. (2000) Preparation of PCR-quality mouse genomic DNA with hot sodium hydroxide and tris (HotSHOT). Biotechniques 29:5254.

Tsuchiya K, Uzu T (1997) Sneaker male in Octopus. Jap. Jour. Malac 56: 177-181.

Van Heukelem W (1976) Growth, bioenergetics and life-span of Octopus cyanea and Octopus

Peer) reviewing PDF | (2018:10:32128:1:1:NEW 14 Mar 2019) 
733

734

735

736

737

738

739

740

741

742

743

744

745

746

747

748

749

750

751

752

753

maya. Dissertation, University of Hawai'i.

Voight JR (2002) Morphometric analysis of male reproductive features of octopodids (Mollusca: Cephalopoda). Biol Bull 202:148-155. doi: 10.2307/1543651

Voight JR, Feldheim KA (2009) Microsatellite inheritance and multiple paternity in the deep-sea octopus Graneledone boreopacifica (Mollusca: Cephalopoda). Invertebrate Biology 128:2630.

Wada T, Takegaki T, Mori T, Natsukari Y (2010) Sperm removal, ejaculation and their behavioural interaction in male cuttlefish in response to female mating history. Animal Behaviour 79:613-619. doi: 10.1016/j.anbehav.2009.12.004

Wells MJ (1978) Octopus. Halsted Press

Wells MJ, Wells J (1972) Sexual displays and mating of Octopus vulgaris Cuvier and O. cyanea Gray and attempts to alter performance by manipulating the glandular condition of the animals. Animal Behaviour 20:293-308.

Wigby S, Chapman T (2004) Sperm competition. Curr Biol 14:R100-2.

Wodinsky J (2008) Reversal and transfer of spermatophores by Octopus vulgaris and $O$. hummelincki. Mar Biol 155:91-103.

Ylitalo HA, Watling L, Toonen RJ (2014) First description of hatchlings and eggs of Octopus oliveri (Berry, 1914) (Cephalopoda: Octopodidae). Molluscan Research 1-5. doi: $10.1080 / 13235818.2013 .860871$ 


\section{Table $\mathbf{1}$ (on next page)}

Summary of microsatellite markers used for this study

Novel species-specific microsatellite markers developed for Octopus oliveri and used in this study, the primer and tagged sequences, annealing temperature, size and levels of polymorphism. 
Table 1. Novel species-specific microsatellite markers developed for Octopus oliveri and used in this study, the primer and tagged sequences, annealing temperature, size and levels of polymorphism. Sequences and additional loci not used in this study are provided in the Supplementary Materials.

\begin{tabular}{|c|c|c|c|c|c|c|c|c|}
\hline Locus & Motif & Primer Sequence $\left(5^{\prime}-3^{\prime}\right)$ & $T_{\mathrm{a}}$ & $\begin{array}{c}\text { Size } \\
\text { Range } \\
\text { (bp) } \\
\end{array}$ & $\mathrm{N}_{\mathrm{A}}$ & $\mathrm{H}_{\mathrm{O}}$ & $\mathrm{H}_{\mathrm{E}}$ & $\begin{array}{c}\text { Freq of } \\
\text { Nulls } \\
\end{array}$ \\
\hline Octoli_003 & $(\mathrm{TAGA})_{12}$ & $\begin{array}{l}\text { F: T1-GCACGTTGTACGCGATTC } \\
\text { R: ATATGCATGAAGACGCAACTC }\end{array}$ & 62 & $\begin{array}{l}154- \\
200\end{array}$ & 11 & 0.888 & 0.856 & 0.018 \\
\hline Octoli_007 & $(\mathrm{TATG})_{12}$ & $\begin{array}{l}\text { F: T2-CGCAGACGAGGAATCAATAG } \\
\text { R: GGAGAACAGACACAAGAACACAG }\end{array}$ & 62 & $\begin{array}{l}152- \\
184\end{array}$ & 9 & 0.718 & 0.816 & 0.063 \\
\hline Octoli_017 & $(\text { TATG })_{8}$ & $\begin{array}{l}\text { F: T2-AGCAACACGATGGCCTCTAC } \\
\text { R: AGTCCAACAAGCTTCGATCC }\end{array}$ & 60 & $\begin{array}{l}180- \\
202\end{array}$ & 5 & 0.569 & 0.521 & 0.048 \\
\hline Octoli_022 & $(\mathrm{TGA})_{21}$ & $\begin{array}{l}\text { F: T1-AGCCATGTGGTTGAGAACG } \\
\text { R: GCGTGCCTCTCTTCATCAG }\end{array}$ & 60 & $\begin{array}{l}239- \\
287\end{array}$ & 14 & 0.943 & 0.902 & 0.022 \\
\hline Octoli_023 & $(\mathrm{GAT})_{20}$ & $\begin{array}{l}\text { F: T3-GCCATGAATTCCAAGTAACTAACC } \\
\text { R: CATCGTCATACGCCATCATC }\end{array}$ & 60 & $\begin{array}{l}160- \\
199\end{array}$ & 15 & 0.856 & 0.846 & 0.007 \\
\hline
\end{tabular}

T1: PET-5'-GGCTAGGAAAGGTTAGTGGC-3'; T2: 6-Fam-5'-TCATACATGTCTCTCAGCGTAAAC-3'; T3: VIC-5'-

GACTATGGGC GTGAGTGCAT-3'; T4: NED-5'-ACCAACCTAGGAAACACAG-3' , $T_{\mathrm{a}}$ : Annealing temperature $\left({ }^{\circ} \mathrm{C}\right), \mathrm{N}_{\mathrm{A}}$ : 4

Number of alleles, $\mathrm{H}_{\mathrm{O}}$ : Observed heterozygosity, $\mathrm{H}_{\mathrm{E}}$ : Expected heterozygosity 


\section{Table 2 (on next page)}

Factors resulting in greater proportion of offspring sired by male 0 . oliveri.

Variable importance in the proportion of offspring sired among males of Octopus oliveri who sired multiple paternity broods. Containing models refers to the sum of the weights of all models that include a variable (see Supplementary Material for complete AIC model selection table). 
1 Table 2. Variable importance in the proportion of offspring sired among males of Octopus oliveri

2 who sired multiple paternity broods; the sum of the weights of all models that include a variable

3 (see Supplementary Materials for complete AIC model selection table).

\begin{tabular}{lccccc}
\hline & $\begin{array}{c}\text { Male } \\
\text { Order }\end{array}$ & $\begin{array}{c}\text { Size of } \\
\text { Male }(\mathrm{g})\end{array}$ & $\begin{array}{c}\text { Number of } \\
\text { Arch and } \\
\text { Pumps }\end{array}$ & $\begin{array}{c}\text { Mating } \\
\text { Time } \\
(\mathrm{sec})\end{array}$ & $\begin{array}{c}\text { Removal of } \\
\text { Sperm } \\
\text { Packet }\end{array}$ \\
\hline \hline Importance: & 0.88 & 0.82 & 0.21 & 0.13 & 0.12 \\
$\mathrm{~N}$ & & & & & \\
$\begin{array}{l}\text { containing } \\
\text { models }\end{array}$ & 16 & 15 & 16 & 15 & 16 \\
\hline
\end{tabular}

4 


\section{Figure 1}

Design of octopus breeding experiment

The top row represents the females used in the experiment while the bottom row is representative of the males of varying sizes (small medium, and large). Each pair is connected with the mating order listed at the top near the female. For example, female $i$ mated with male $\mathrm{A} 1^{\text {st }}$, male $\mathrm{B} 2^{\text {nd }}$, and male $\mathrm{C} 3^{\text {rd }}$. Six separate females and three separate males were used for each of the four mating experiments that were run. Due to the death of some individuals, only 62 mating events between the octopuses were recorded (raw data presented in Supplementary S1). A tissue biopsy from the arm of each female and male following the mating experiments provided the DNA for paternity testing. 


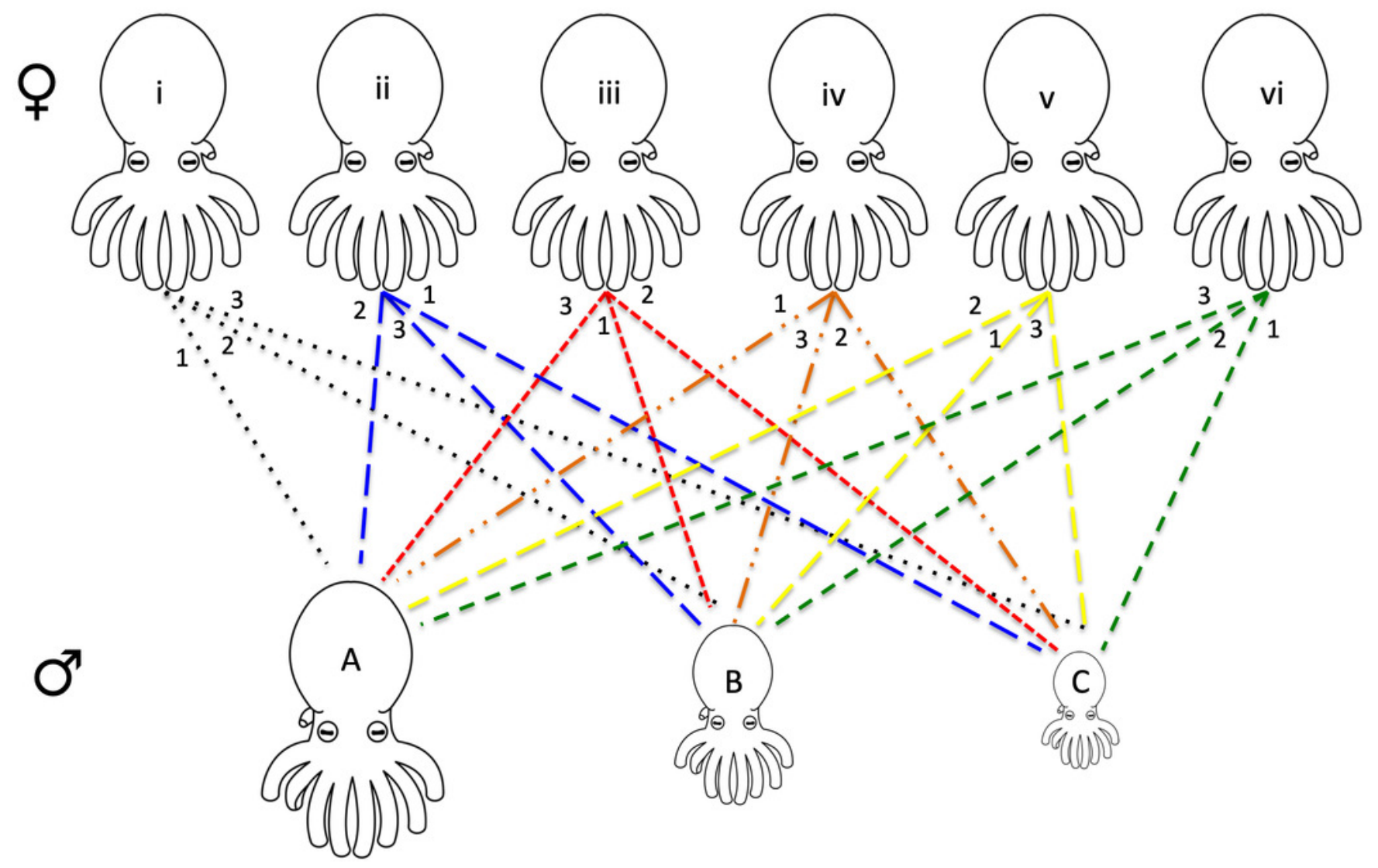




\section{Figure 2}

Images of mating behaviors captured from video.

Video stills of four mating pairs of Octopus oliveri in the beak-to-beak mating position.

Females are indicated as the letter $A$ and males as the letter $B$ in each frame.

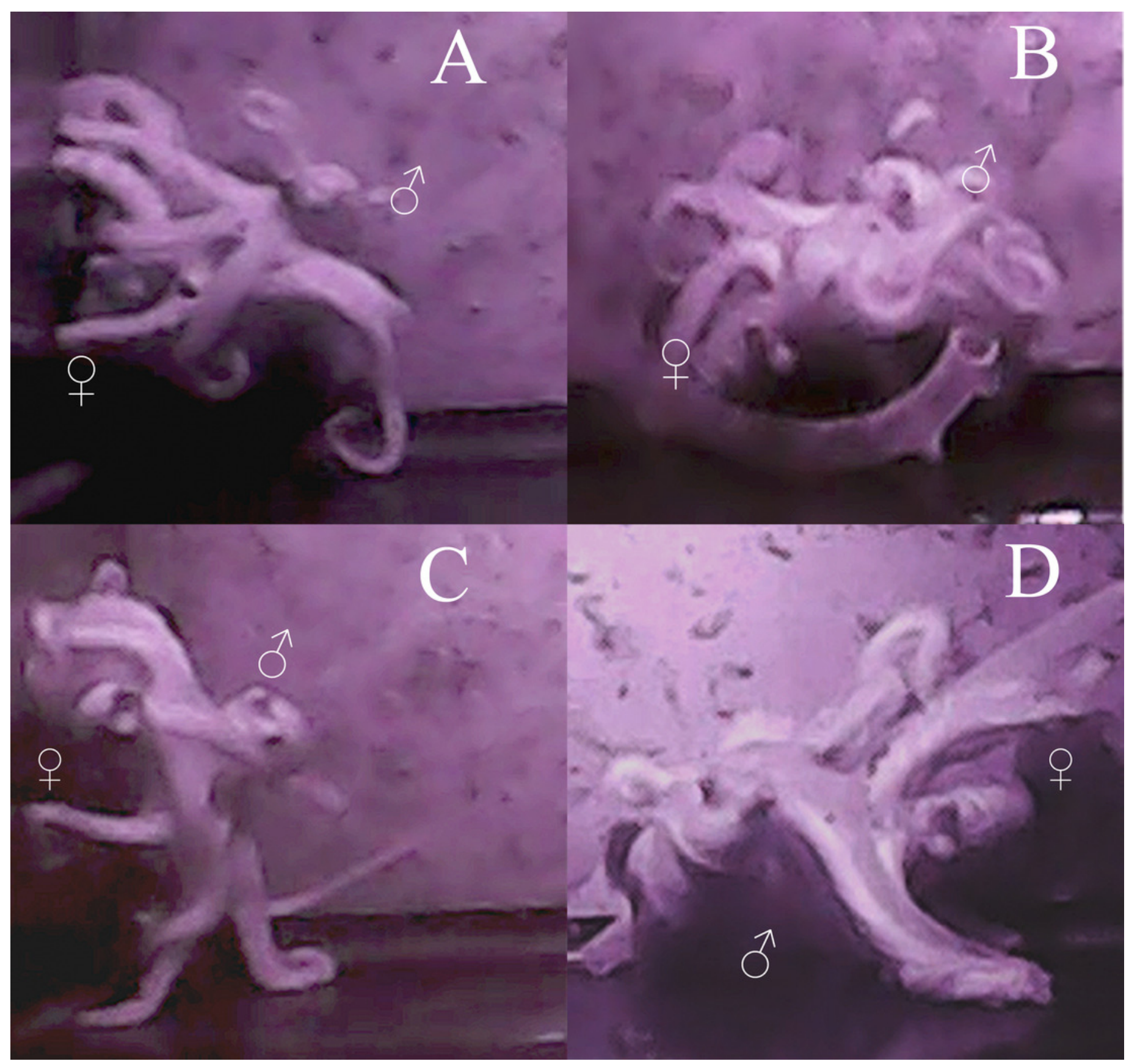




\section{Figure 3}

Role of mate order in determining number of offspring sired.

Percentage of eggs sired vs. male order in mating trials with Octopus oliveri, before rerunning genotypes of unassigned eggs. Here, group 0 refers to all wild males lumped into a single category as "other" mating prior to the experiment which is the highest proportional fertilization success among tested egg masses. $p<0.01$ for all between 0,2 and 3, Residual Std. Error $=0.19, \mathrm{df}=23, \mathrm{R}^{2}=0.51 .{ }^{*}=$ significant.

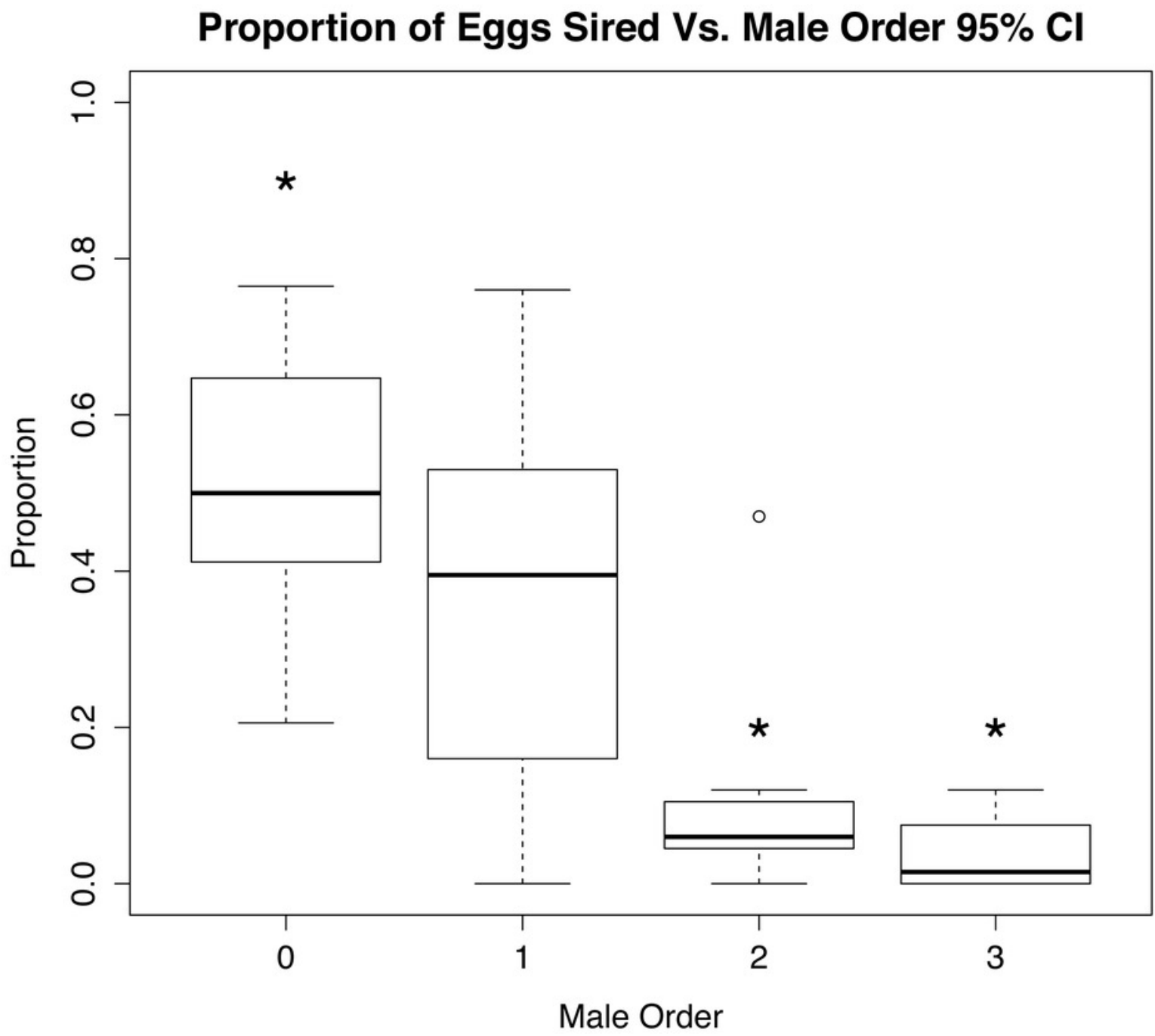




\section{Figure 4}

Role of mate order in determining number of offspring sired.

Percentage of eggs sired versus male order in mating trials with Octopus oliveri after GERUD was rerun on "Other" males from putative matings that occurred in the field before collection. Here, group 0 refers to wild males separated by likely genotype into individuals, which partitions the pre-experiment mating among several individuals and reduces the mean success of each relative to the lumped "other" category presented in Fig. 2. p > 0.001 for both 0 and 1. Residual Std. Error $=0.15, \mathrm{df}=44, \mathrm{R}^{2}=0.28{ }^{*}=$ significant.

\section{Proportion of Eggs Sired Vs. Male Order}

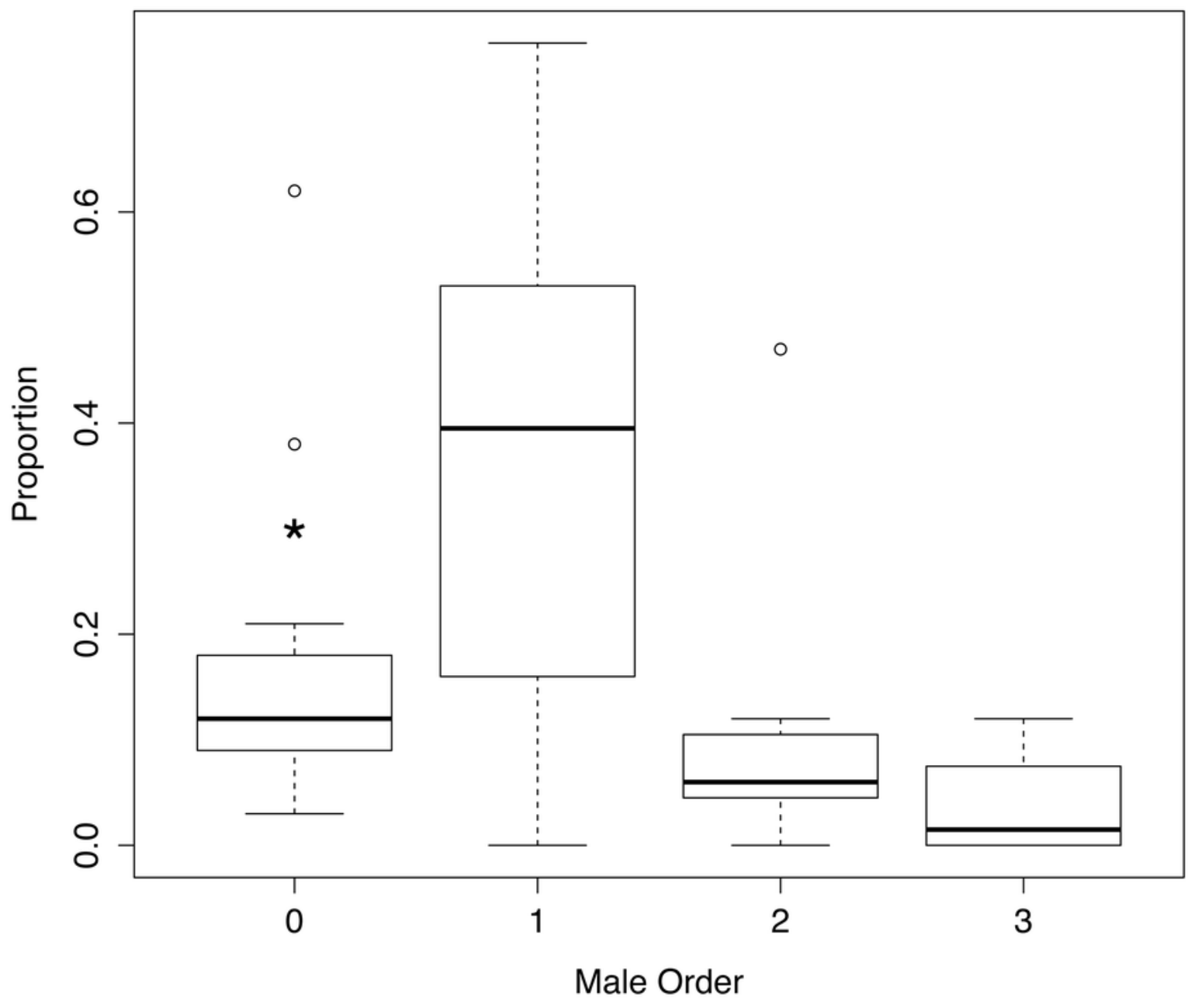




\section{Figure 5}

Explanatory variables in paternity analyses.

Single linear regression / one-factor ANOVA plots of possible explanatory variables in paternity analysis. Male mating order (likelihood ratio $x^{2}=23.3, d f=2, p<0.001$ ), Male size in grams (likelihood ratio $x^{2}=11.8, d f=1, p<0.001$ ), Number of arch and pumps observed in mating trial (likelihood ratio $x^{2}=3.8, d f=1, p<0.05$ ), Mating time in seconds (likelihood ratio $\mathrm{x}^{2}=5.8, \mathrm{df}=1, \mathrm{p}<0.01$ ), Number of times a female removed a sperm packet (likelihood ratio $\mathrm{x}^{2}=5.1, \mathrm{df}=1, \mathrm{p}<0.05$ ), Male size relative to female (I: large, m: medium, or approximately equal to female size, $s$ : small) (likelihood ratio $x^{2}=3.9, d f=1, p=0.13$ ).

A

Male Order Effect

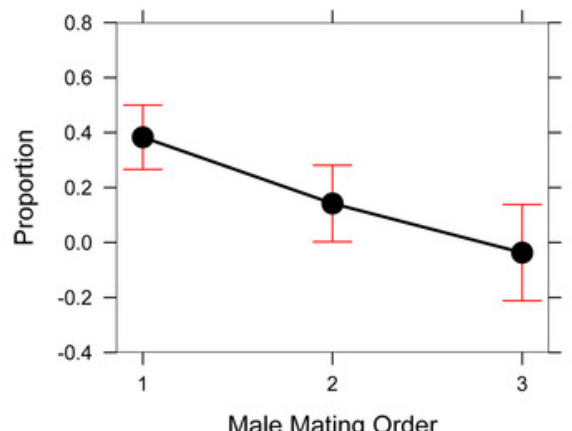

$\mathrm{D}$ Mating Time Effect

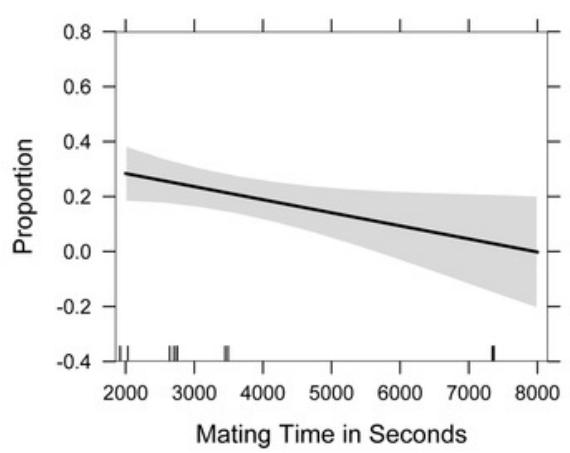

B

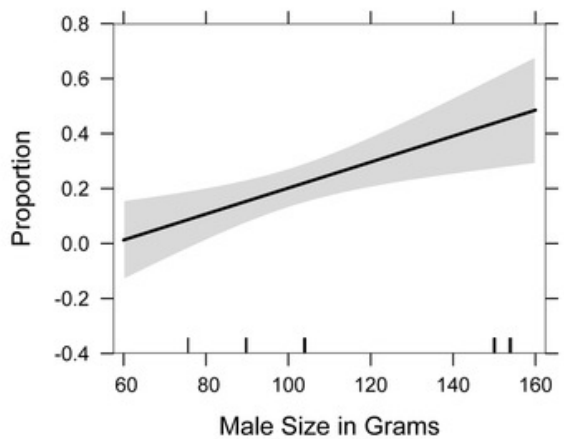

E

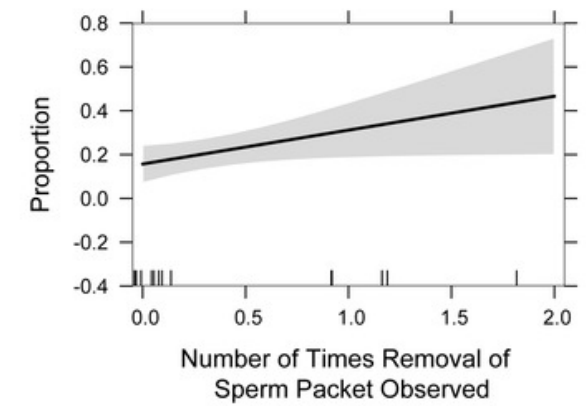

C Number of Arch and Pumps Effect

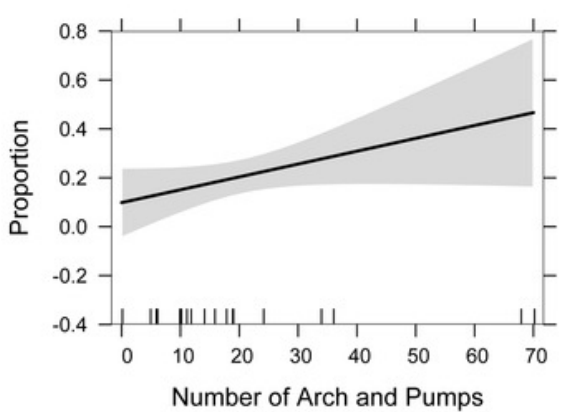

F

Male Size Relative to Female Effect

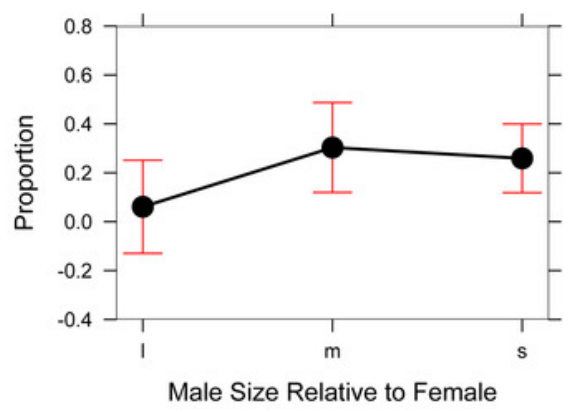

